\title{
Re-considering the nature of work in complex adaptive organisations - Fluid work as a driver of learning through work
}

\author{
Amanda L. Lizier \\ University of Technology Sydney, School of International Studies and Education
}

\begin{abstract}
Purpose

This paper draws on data from a study of professionals' experiences of work and learning framed by a complex adaptive systems approach to examine the nexus of work and learning in complex adaptive organisations.

\section{Design/methodology/approach}

The study used an adapted phenomenographic approach and the complex adaptive systems conceptual framework (CAOCF) to analyse data from semi-structured interviews with fourteen professionals from a variety of organisations and industry sectors within Sydney, Australia.

\section{Findings}

The findings highlight that work in complex adaptive organisations is best described as fluid work. Further, the findings suggest that fluid work influences professionals towards flexible learning approaches that take place in the flow of work.

\section{Originality}

This paper empirically demonstrates the nexus of work and learning as experienced by professionals in their day-to-day work, and the ways in which fluid work influences flexible and adaptable learning through participation in work.

\section{Introduction}

This paper presents findings from an empirical study that investigated the nexus of work and learning in complex adaptive organisations. Using a complex adaptive systems approach, the study reported here provides insights into the way in which fluid work influences flexible learning through participation in work. Building on earlier work using complexity to explore work and learning (e.g. Marsick et al, 2017), the study reported here integrates the acceptance of participation as central to understanding work and learning in investigating the two phenomena concurrently. Importantly, the 
study foregrounds the lived experiences of individuals to seek insights into the micro-level of complex adaptive organisations as distinct to the greater research emphasis given to the macro aspects of the system-level of organisations (e.g. Chiva et al., 2014, Chiva and Habib, 2015).

Complexity approaches refer to the theoretical and analytical tools used to investigate specific types of systems called complex systems. A complex system is one where there is a network of components with little or no central control and simple operational rules that bring about complex collective behaviours (Mitchell, 2009). Examples of complex systems include computer networks, epidemic disease spreading, bee colonies, and, of interest here, human social systems. Complexity approaches have been identified within the organisation studies literature as being an effective theoretical and conceptual framework for understanding organisations (e.g. Tsoukas and Dooley, 2011, Uhl-Bien and Arena, 2017). The workplace learning literature has also adopted complexity approaches as having potential for offering new understandings of learning and practice at work (Davis, 2012, Hager and Beckett, 2019). Johnsson and Boud (2010), for example, used complexity theory as the basis for a study exploring the emergent learning of workers who were temporarily 'acting up' in more senior roles.

A key assumption of complexity approaches is that complex systems adapt. Both the agents and the system change their behaviours to increase their chances of success or survival, usually through learning or adaptation. When a complex system contains agents that seek to adapt, these are called complex adaptive systems (Holland, 1995). Complex adaptive systems contain agents that respond to external and internal inputs by adapting, forming and changing their strategies for working within systems. From this perspective, it is assumed that these systems learn. It is the adaptive nature of complex adaptive systems that is of interest in exploring work and learning in organisations in this study. The workplace learning literature largely adopts the broader terms of complexity theory or complexity approaches with relatively few studies adopting the more specific concept of complex adaptive systems that frames this study (Chiva et al., 2014, Chiva and Habib, 2015, Jacobson et al., 2019, Jones and Corner, 2012).

Adopting a complex adaptive systems approach takes up discourses around the changing nature of work due to rapid change influenced by globalisation, technology, and neoliberal policies (Harteis et al., 2014). More recently, complexity approaches have also been used to make sense of informal and incidental learning through the COVID-19 pandemic (Watkins and Marsick, 2021). Doing so also takes up theoretical shifts in the workplace learning literature towards practice (Hager, 2011) or complexity approaches (Fenwick et al., 2011), reflecting a growing recognition of the changes in contexts of work and learning in developed economies. Foregrounding the experiences of individual 
professionals within organisations responds to gaps identified in the literature highlighting that, while organisations have been studied as complex and complex adaptive systems, there has been less research into the experiences of individuals within such systems. Investigating the work and learning experiences of individuals, here referred to as professionals, within complex adaptive organisations will add to current understandings of work and learning within the "fluid, ever-shifting contexts" (Hopwood, 2016, p.75) in which professionals now work. This paper's contribution is to empirically demonstrate the nexus of work and learning as experienced by professionals in their dayto-day work, and the ways in which fluid work influences flexible and adaptable learning through participation in work. The purpose is to understand how the nature of fluid work tasks, as opposed to primarily considering the role of context, influences learning through participation in work.

Complex adaptive organisations is the key concept that incorporates complex adaptive systems approaches into the study. A complex adaptive organisation is an organisation that is an example of a complex adaptive system and shows evidence of four key elements identified from the literature on complex adaptive systems (Barabási and Albert, 1999, Holland, 1995, Watts and Strogatz, 1998) and the work and learning literature (Kersh, 2015, Vähäsantanen et al., 2017) as having the highest potential to provide insights into organisational complexity. The four elements that describe complex adaptive organisations, known as the Complex Adaptive Organisations Conceptual Framework (CAOCF), are - emergence, adaptation, complex social networks, and agency. Such organisations are comprised of individual professionals who learn and adapt, act with agency, and interact through complex social networks as part of their everyday work (Lizier, 2017).

\section{The study}

The study investigated how professionals experience work and learning as inter-related phenomena within complex adaptive organisations. Participants are referred to as professionals describing the nature of their work, which was office-based. Traditionally, "professionals" were identified as individuals working within a profession such as law or medicine. However, over time, professionals have been increasingly defined as office-based workers more generally, often with discretion over the completion of their work (Fuller and Unwin, 2010).

Following ethics approval from the Human Research Ethics Committee at the University of Technology Sydney, professionals were identified using the professional networks of the researcher and a convenience sample (Saumure and Given, 2008) was taken from across a range of industries, organisation types, and hierarchical levels. The sampling process was purposive, common in phenomenography (Yates et al., 2012), involving a series of strategic choices about the professionals and how their selection might further the aims of the research (Palys, 2008). Professionals were 
initially identified as individuals who were willing to participate. To ensure that willing participants worked in organisations that would be considered as complex adaptive organisations a further assessment was undertaken using desktop research, which included reviewing company websites and organisational documents. The CAOCF was then used to analyse the organisational documents and determine that the professionals identified for interviews did indeed work in organisations that could be considered complex adaptive organisations.

\section{Complex Adaptive Organisation Conceptual Framework (CAOCF)}

The CAOCF framed the study and was used as part of the analysis, setting out the ways in which complex adaptive systems approaches have been adopted and customised specifically for this study of professionals' work and learning experiences. The CAOCF offers a way in which to understand organisations as complex adaptive systems using the four key elements of complex adaptive organisations - emergence, complex social networks, adaptation, and agency. Such organisations are comprised of individual professionals who learn and adapt, act with agency, and interact through complex social networks as part of their everyday work (Lizier, 2017). Emergence in a complex adaptive system is a core phenomenon whereby outcomes are not completely random and yet cannot be predicted or directed, a situation requiring a high degree of adaptation from professionals (Mitchell, 2009). Emergence, in turn, presents constant opportunities for adaptation for the professionals within complex adaptive organisations. Learning and adaptation are critical parts of complex adaptive organisations which have important implications for the ways in which professionals learn and work within them. Complex social networks are a specific category of social networks defined by patterns of interactions between people or groups of people (Scott, 2000). Within the context of complex adaptive organisations, complex social networks assist in conceptualising the flows of information through the network (Borgatti and Halgin, 2011). Network "clustering" (e.g., through work teams or social cliques) is a term used to describe how every person is more or less connected to people in the rest of the network through a surprisingly small number of connections (Davis and Sumara, 2006). Finally, for the purposes of this study, agency was defined as a continuum along which empowered and self-aware professionals have a greater or lesser number of opportunities to make decisions and take intentional actions to learn and adapt to the present needs of their work and work context (Billett, 2011, Eteläpelto et al., 2013, Vähäsantanen et al., 2017). 


\section{Method}

Semi-structured interviews were conducted with fourteen professionals, in line with the usual phenomenographic practice of having around ten to fifteen participants to ensure a reasonable change in variation (Trigwell, 2000). Overall, the professionals worked within nine different organisations, representing sectors engaged in professional services, a professional association, banking, retail, radio and television production, aviation, scientific research, and pharmaceuticals. These included publicly listed, not-for-profit, and government organisations where the professionals worked as executives, senior managers, managers, technical professionals, and in administration.

The semi-structured interviews used a combination of direct questions and critical incident questions (Butterfield et al., 2005) to encourage participants to reflect on specific learning situations and describe their experiences of them. The interview was established by asking general questions about the organisation and the professional's role within it before moving on to discuss their general experiences of learning at work. Critical incident questions were then used as a tool to ask professionals to reflect on a situation where they felt learning had occurred in their job and to identify which part of that experience they felt constituted learning. For example, professionals were asked how they "learned the ropes" when they first started in their job and to describe their experience at a time when they needed to learn something new. Interviews were digitally recorded before being transcribed and analysed.

\section{Analysis}

The analysis adopted the iterative approach common to phemonenographic studies, first by analysing whole transcripts, and then revising the emerging categories of description over a period of around twelve months. Using the four elements of the CAOCF as a starting point, full transcripts were reviewed multiple times to develop a list of themes which were then refined to develop a coding framework that formed the starting point for the categories of description which were refined over a period of around one year. Reliability was assessed by working backwards from the final categories and re-coding the data in a post-hoc analysis to determine if there was direct support for the categories. While this is not traditionally part of the phenomenographic approach, it provided an opportunity to verify that the categories of description were supported by the data. In addition, interpretive guidelines adapted from Sandbergh (1997) by Patrick (2000) were also used to guide the analysis and ensure reliability through an open orientation to the transcripts and analysis. The phenomenographic approach was further adapted by investigating two interrelated phenomena simultaneously rather than the general practice of focusing on lived experiences of a single 
phenomenon, often learning (e.g. Bliuc et al., 2012, Wilhelmsson et al., 2010). While earlier studies exploring two phenomena have conducted separate analyses (Bailey, 2015), this study analysed experiences of work and learning simultaneously.

\section{Fluid work}

The findings indicate that professionals in complex adaptive organisations experience work along a continuum of fluidity that is influenced by organisational complexity. The degree of work fluidity, in turn, influences professionals' experiences of learning as being primarily through work, from others in their networks, and, to a lesser extent, via structured learning provided by their organisation. The concept of fluid work is therefore a key one in understanding experiences of work and learning in complex adaptive organisations.

The term "fluid" is used to describe the experience of work that emerged from the data, where participants described work that was unpredictable requiring frequent and rapid pivots to adapt as required and where professionals had a relatively high degree of autonomy over how they completed to their work tasks. The term fluid is used here as a contrast to day-to-day work tasks been seen as things that can be structured and planned. Fluid work as it is used in this study differs from other usages of the term in the literature that have tended to focus on describing fluid work contexts rather than also fluid work tasks as done here (González-Martínez et al., 2016, Xinwei et al., 2016). The study reported here highlights that, while the context of work is important, we need to go the extra step of exploring how context shapes work tasks and how that experience of work influences learning.

\section{Influence of organisational complexity on fluid work}

Interview data suggested that the degree of work fluidity professionals experience is shaped by organisational complexity which was framed using the CAOCF (Lizier, 2017). Considering work and learning through the lens of the four elements of the CAOCF - emergence, adaptation, social networks and agency - helped to contextualise professionals' experiences by examining the impact of organisational complexity (via the four key elements) on individual experiences of work and learning.

Adaptation was key to experiences of work and learning with professionals describing their experiences of work in complex adaptive organisations as requiring ongoing learning and adaptation influenced by what emerged through the course of their day-to-day work. The ability to adapt enabled professionals to adjust incrementally and transformatively to the demands of complex adaptive organisations. As one professional commented: 
Everything changes now. You kind of just go bend with everything and go with the flow with whatever's happening, you know. You can plan your day to look like something but it never pans out that way. (Systems analyst, professional association)

Further, a sales manager noted that the most important skill for them at work was to:

...be able to be adaptable to change because there's a lot of things that happen on a daily basis that, whilst you could be the most organised person in the world, you need to be able to adapt and change if things don't go according to that plan. It's a very turbulent environment... (State sales manager, professional association)

Emergence is strongly related to adaptation, playing an important part in the fluidity of work and subsequent experiences of learning. Throughout the interviews, the professionals identified the highly time pressured and changeable nature of their work, requiring constant adaptation. A scientific manager described both the emergent nature of their day-to-day work as well as the ways in which this influenced their learning through work:

...you apply for a promotion, you don't get it, you learn about it. Every new process that you have to implement that you learn about, every new initiative that comes along ... you have to think about how that should be rolled out or what the best way of doing some procedure is. You're always learning. (Scientific manager, Government research organisation)

In observing that they are "always learning", the scientific manager identifies a thread that has been well-established in work and learning research, that people learn through participation at work. Framing this experience in terms of emergence offers a potential explanation of why this might be the case. Responding to emergence within the organisational system suggests a situation where professionals are constantly called on to learn and adapt.

Working within and between network clusters was identified by the professionals interviewed as central to their work and learning. One professional, for example, discussed the importance of building their connections through nurturing relationships to influence others so that they could assist them:

...it's those relationships that you're developing with others and how you're able to influence others in regards to say, assisting you with the job or getting information from them so you can hone your job in that way. (Radio network manager, Television and radio production) 
Professionals described seeking out colleagues within their team to learn from, or turning to their connections to seek introductions to people with more specific expertise. Some professionals also described seeking advice from outside of their work teams and from outside their organisation. An executive assistant gave a detailed account of nurturing a community of colleagues in similar roles,

...you're not skilled in everything all of the time so I may not do PowerPoint now for six months or 12 months but you know, then a presentation comes back and you have to do it. .... that's what I find our Business Support Group so helpful with because we've got this network of people that you can email and it doesn't make you feel like you should know it in this role. (Executive assistant, Pharmaceuticals)

Within complex adaptive organisations, building and maintaining social connections was critical for learning and adaptation through facilitating the flow of information. It was a process whereby professionals actively engaged in seeking connections and building relationships to meet their own work and learning needs as well as to learn to navigate and utilise existing structures. In one such example, a systems analyst described how their learning was prompted by changes to their job within a new and growing department.

I guess time went on, the role got busier. We got more responsibilities as a department and I really had to use relationships within the organisation to get things done, to get processes and to learn the ropes. Because there was no one there to teach me how to do this, so I would have to go to each division and learn something from each division.

(Systems analyst, professional association)

The findings further indicated that the professionals exercised a high degree of agency within their job, with a high level of flexibility in determining their daily goals and tasks as well as longer-term goals within the boundaries of their job responsibilities.

The ability to act with agency made a significant contribution how professionals experienced fluidity within jobs where they had to respond to multiple and often-competing demands. This is demonstrated in the following excerpt from an interview with the executive assistant to the general manager of a busy marketing department. Although their role was ostensibly to support their manager, the job had grown and changed as the needs of the business and the team had changed, and they found themselves often operating outside of their original job description.

I'm almost like an all-in-one shampoo, conditioner and body wash .... I report directly to the GM [General Manager]. I look after him. I also support the team. We have a team administrator as well who, I kind of help her along with stuff as well .... And then I sit on 
lots of projects and I also look after a program that we run .... and then I help support administration on a digital project that we have as well. (Executive assistant, professional association)

In using the metaphor of being "an all-in-one shampoo, conditioner and body wash" they encapsulate not only the fluidity of their job generally in being "all things to all people" but also their agency in negotiating how their work was carried out. The excerpt from the administration assistant also highlights the paradox of fluid work that even as the professionals exercise a high degree of agency they nevertheless use terms such as "reactive", "overwhelmed", and "out of control" when referring to their day-to-day work. The transcripts generate a sense of a constant and somewhat erratic stream of work to which the professionals felt they needed to constantly react and adapt with little opportunity for consideration or reflection, further demonstrating the impact of emergence on experiences of work through the creation of dynamic contexts of change and uncertainty. Interviews indicated how work and learning was experienced as a continuous process of adaptation to the demands of emergence, supported by professional's networks, and achieved through the exercise of their agency. Emergence played a central part in the fluidity of work and professionals' subsequent experiences of learning primarily through work.

\section{Influence of fluid work on learning}

The nature of fluid work is entwined with learning in that it influences professionals towards learning via participation more than through more traditional forms of learning in organisations such as faceto-face or online training. In contrast, the organisations employing the professionals tended to privilege structured and formalised forms of learning over learning in the flow of work (Lizier and Reich, 2021). The interviews confirmed that the professionals learned primarily through work, specifically, through solving problems related to their work. For example, a professional from pharmaceuticals described how:

I guess that a lot of my learning is self-led, so I might seek out some new information, I might do something new in my job and I have to learn how to do that as a result. I did that just last year. Something I've never done before and just figured it out for myself. (Regional remuneration and benefits manager, Pharmaceuticals)

The greater the degree of work fluidity in one's job, the greater the impetus towards learning through work. In other words, when professionals were presented with work that demanded that they learn and adapt quickly, work across and within networks, and exercise agency in doing so, then learning through work was the most commonly used form of learning to meet the speed of learning 
and adaptation required to successfully complete that work. The following excerpt from an interview with a knowledge manager gives some insight into how they experienced fluid work day-to-day.

...we had a discussion with a few people and said how about we run a workshop for representatives from our clients around the future of Australian banking. How about we do that as a scenario planning activity? So basically, I hadn't done that before, so I said "I'll do that" because nobody else was going to do it. So I went off and did it. That's pretty much how the learning occurred. I read a few books, I talked to a few people... I put out a few questions on the Jive platform and got a few useful responses back from people from elsewhere. Then I just went off and did it. (Knowledge manager, professional services)

The excerpt above highlights both work fluidity, in terms of adapting to project requirements and opportunities as they present themselves, as well as how these changing work requirements then impacted their experiences of learning. The knowledge manager was also asked to participate in a project outside their day-to-day job as a knowledge management specialist. The project was not originally part of their job description and it presented new opportunities for learning and professional development, which they took up enthusiastically. A learning projects manager from the bank had a similar experience, where they described:

I was tapped on the shoulder by the head of our team and offered the opportunity to do it [a more senior role]. And that was pretty much it. I said yes and it was mine and any gap between what I was currently able to do and what I needed to be doing the role was ... I am sure I probably could have asked for more but, at the time, it very much felt like I guess I better learn how to do this myself. (Learning projects manager, Banking)

In a similar way to the knowledge manager, the learning projects manager was required to respond to the emerging requirements of their work and of the organisation. Their journey of learning and adaptation was through the course of learning their new job.

While context is undoubtedly important in shaping learning in the workplace, these findings highlight the influence of day-to-day tasks on professional's learning approaches. Earlier research has investigated the role of context in work and learning (Billett, 2001, Fuller and Unwin, 2010, Gijbels et al., 2012, Kyndt et al., 2016) but has tended to focus on how the context encourages or restricts learning. Whereas the emphasis of such research "lies on conditions, possibilities or occasions created to make workplace learning possible" (Kyndt et al., 2009, p.370), the findings highlight the importance of considering the nature of the work itself in understanding work and 
learning in complex adaptive organisations. Research by Gijbels et al. (2012), for example, has highlighted the importance of examining job characteristics in terms of work and learning. However, their research has focused on how job demands and control positively or negatively influence interpersonal variables such as stress or well-being, also finding a positive correlation between job demands and job control with "work-related learning behaviour" (p. 425). They have noted, however, that additional qualitative research is needed to further investigate these findings. The study reported here has undertaken such research, finding that experiences of work that is fluid are central to understanding how professionals' experience learning in complex adaptive organisations.

The findings from this study have indicated that, within complex adaptive organisations, professionals learn through participation in fluid work. Yet much of the current work and learning research has focused instead on learning as the object of study (Tynjälä, 2013), largely neglecting detailed examinations of the nature of work tasks and their influence on professionals' experiences of learning, particularly from a complex adaptive systems approach (Holland, 1995). Research has been conducted using concepts such as learning-conducive work (Skule, 2004), expansive and restrictive practices (Fuller and Unwin, 2010), and workplace affordances (Billett, 2001), which has investigated the role of learning environments on work and learning. What the frameworks and concepts of Skule (2004), Billett (2001), and Fuller and Unwin (2010) have in common, is that each of them focuses primarily on the work environment and the ways in which it shapes learning. Such frameworks have offered significant insights into understandings of work and learning in terms of the workplace contexts which best support learning through participation. An under-theorised area in this literature is how the context influences day-to-day work tasks and learning through participation. In considering professionals' experiences of work and learning, this study aims to contribute to a more nuanced theorisation of the nature of work at a day-to-day task level in the context of complex adaptive organisations.

\section{Limitations}

Limiting the study to office-based professionals within a major city in Australia necessarily places some limitations on the data given the cultural context. Utilising professional networks to gather a purposive sample also has potential to focus the research on only on particular network clusters. The use of office-based professionals also presented challenges in terms of the interviews. While participants had initially agreed to an interview of up to one hour in duration, it was found in practice that this was not always possible since the interviews largely took place within the 
workplace and within work hours. Interruptions and unexpected issues arising for professionals required a flexible approach to both the duration and structure of the interviews.

\section{Implications}

Based on these findings, learning and development systems and practices need to negotiate a fine line between structure and flexibility with structured learning activities shown as less relevant to the requirements of fluid work. From the perspective of workplace learning professionals and others involved in employee development, learning and development systems and practices need to privilege informal and incidental learning over structured activities such as courses and seminars. In support of such changes, related organisational systems such as employee development, performance review, and talent planning also need to adapt to recognise the critical importance of experience in learning over existing emphases on the acquisition of credentials. Further lines of inquiry could investigate how organisations could adopt more adaptive and flexible learning and development systems and practices and the cultural shifts required to effect such changes given the tensions in complex adaptive organisations between rhetoric and practice in learning (Lizier and Reich, 2021).

\section{Conclusion}

The findings of this study indicated that fluid work and learning are interrelated and, as such, need to be considered together to gain a full understanding of work and learning in complex adaptive organisations. Considering experiences of work as fluid and the ways in which fluid work influences experiences of learning makes a significant contribution to the understanding and practice of work and learning within increasingly complex organisational contexts. Further, identifying organisations as complex adaptive organisations has important implications for new ways to support learning for professionals and ways to improve learning and development systems and practices. Recognising that professionals experience work as fluid and that it is entwined with learning challenges existing learning and development systems and practices that tend to privilege structured and formalised forms of learning over learning in the flow of work (Lizier and Reich, 2021). This requires a shift in learning and development systems and practices from more traditional forms of learning in organisations such as face-to-face or online training towards greater action to facilitate and recognise learning via participation. The findings from this study suggest that, for professionals and organisations to best respond to increasing complexity, learning in complex adaptive organisations 
needs to be aligned with, and acknowledge, the interplay of organisational complexity, fluidity of work, and experiences of learning through participation.

\section{References}

Bailey, M. 2015. Professional development of HR practitioners - A phenomenographic study. European Journal of Training and Development, 39, 220-238.

Barabási, A.-L. \& Albert, R. 1999. Emergence of scaling in random networks. Science, 286, 509-512.

Billett, S. 2001. Learning through work: Workplace affordances and individual engagement. Journal of Workplace Learning, 13, 209-214.

Billett, S. 2011. Subjectivity, self and personal agency in learning through and for work. In: Malloch, M., Cairns, L., Evans, K. \& O'Connor, B. N. (eds.) The SAGE Handbook of Workplace Learning. London: SAGE Publications Ltd.

Bliuc, A.-M., Casey, G., Bachfischer, A., Goodyear, P. \& Ellis, R. 2012. Blended learning in vocational education: Teachers' conceptions of blended learning and their approaches to teaching and design. The Australian Educational Researcher, 39, 237-257.

Borgatti, S. P. \& Halgin, D. S. 2011. On network theory. Organization Science, 22, 1168-1181.

Butterfield, L. D., Borgen, W. A., Amundson, N. E. \& Maglio, A.-S. T. 2005. Fifty years of the critical incident technique: 1954-2004 and beyond. Qualitative Research, 5, 475-497.

Chiva, R., Ghauri, P. \& Alegre, J. 2014. Organizational learning, innovation and internationalization: A complex system model. British Journal of Management, 25, 687-705.

Chiva, R. \& Habib, J. 2015. A framework for organizational learning: Zero, adaptive and generative learning. Journal of Management and Organization, 21, 350-368.

Davis, B. \& Sumara, D. 2006. Complexity and education: Inquiries into learning, teaching and research, Mahwah, NJ, Lawrence Erlbaum and Associates.

Davis, C. 2012. Practice as complexity: Encounters with management education in the public sector. In: Hager, P., Lee, A. \& Reich, A. (eds.) Practice, Learning and Change: Practice-Theory Perspectives on Professional Learning. Dortrecht: Springer.

Eteläpelto, A., Vähäsantanen, K., Hökkä, P. \& Paloniemi, S. 2013. What is agency? Conceptualizing professional agency at work. Educational Research Review, 10, 45-65.

Fenwick, T. 2012. Complexity science and professional learning for collaboration: A critical reconsideration of possibilities and limitations. Journal of Education and Work, 25, 141-162.

Fenwick, T., Edwards, R. \& Sawchuk, P. 2011. Emerging approaches in educational research: Tracing the socio-material, London, Routledge.

Fuller, A. \& Unwin, L. 2010. 'Knowledge Workers' as the new apprentices: The influence of organisational autonomy, goals and values on the nurturing of expertise. Studies in Vocational and Professional Education, 3.

Gijbels, D., Raemdonck, I., Vervecken, D. \& Van Herck, J. 2012. Understanding work-related learning: the case of ICT workers. Journal of Workplace Learning, 24, 416-429.

González-Martínez, E., Bangerter, A., Lê Van, K. \& Navarro, C. 2016. Hospital staff corridor conversations: Work in passing. Journal of Advanced Nursing, 72, 521-532.

Hager, P. 2011. Theories of workplace learning. In: Malloch, M., Cairns, L., Evans, K. \& O'Connor, B. N. (eds.) The SAGE Handbook of Workplace Learning. London: SAGE Publications Ltd.

Hager, P. \& Beckett, D. 2019. The emergence of complexity: Rethinking education as a social science, Switzerland, Springer Nature.

Harteis, C., Rausch, A. \& Seifried, J. 2014. Discourses on professional learning: On the boundary between learning and working In: Harteis, C., Rausch, A. \& Seifried, J. (eds.) Discourses on Professional Learning: On the Boundary Between Learning and Working. Dortrecht: Springer Science+Business Media. 
Holland, J. H. 1995. Hidden order: How adapation builds complexity, Reading, MA, Addison-Wesley. Hopwood, N. 2016. Professional practice and learning: Times, spaces, bodies, things, Dordrecht, Springer.

Jacobson, M. J., Levin, J. A. \& Kapur, M. 2019. Education as a complex system: Conceptual and methodological implications. Educational Researcher, 48, 112-119.

Johnsson, M. C. \& Boud, D. 2010. Towards an emergent view of learning work. International Journal of Lifelong Education, 29, 359-372.

Jones, R. \& Corner, J. 2012. Seeing the forest and the trees: A complex adaptive systems lens for mentoring. Human Relations.

Kersh, N. 2015. Rethinking the learning space at work and beyond: The achievement of agency across the boundaries of work-related spaces and environments. International Review of Education, 61, 835-851.

Kyndt, E., Dochy, F. \& Nijs, H. 2009. Learning conditions for non-formal and informal workplace learning. Journal of Workplace Learning, 21, 369-383.

Kyndt, E., Vermeire, E. \& Cabus, S. 2016. Informal workplace learning among nurses: Organisational learning conditions and personal characteristics that predict learning outcomes. Journal of Workplace Learning, 28, null.

Lizier, A.L. 2017. Investigating work and learning through complex adaptive organisations. Journal of Workplace Learning 29(7/8): 554-565.

Lizier, A.L. and Reich, A, 2021. Learning through work and structured learning and development systems in complex adaptive organisations: ongoing disconnections. Studies in Continuing Education 43(2): 261-276.

Marsick, V. J., Watkins, K. E., Scully-Russ, E., and Nicolaides, A. 2017. Rethinking informal and incidental learning in terms of complexity and the social context. Journal of Adult Learning, Knowledge and Innovation JALKI 1(1), 27-34.

Mitchell, M. 2009. Complexity: A guided tour, New York, Oxford University Press.

Palys, T. 2008. Purposive sampling. In: Given, L. M. (ed.) The SAGE Encyclopedia of Qualitative Research Methods. Thousand Oaks, California: SAGE Publications, Inc.

Patrick, K. 2000. Exploring conceptions: Phenomenography and the object of study. In: Bowden, J.A. \& Walsh, E. (eds.) Phenomenography. RMIT University Press: Melbourne.

Sandbergh, J. 1997. Are phenomenographic results reliable? Higher Education Research \& Development, 16, 203 - 212.

Saumure, K. \& Given, L. M. 2008. Convenience sample. In: Given, L. M. (ed.) The SAGE Encyclopedia of Qualitative Research Methods. Thousand Oaks, California: SAGE Publications, Inc.

Scott, J. 2000. Social Network Analysis: A Handbook (2nd ed), London, Sage.

Skule, S. 2004. Learning conditions at work: A framework to understand and assess informal learning in the workplace. International Journal of Training and Development, 8, 8-20.

Skule, S. \& Reichborn, A. 2007. Building organisational capability with a learning-conducive workplace. Training and Development in Australia, 34, 5-8.

Tight, M. 2016. Phenomenography: The development and application of an innovative research design in higher education research. International Journal of Social Research Methodology, 19, 319-338.

Trigwell, K. 2000. A phenomenographic interview on phenomenography. In: Bowden, J. A. \& Walsh, E. (eds.) Phenomenography. Melbourne: RMIT University Press.

Tsoukas, H. \& Dooley, K. J. 2011. Introduction to the special issue: Towards the ecological style Embracing complexity in organizational research. Organization Studies, 32, 729-735.

Tynjälä, P. 2013. Toward a 3-P model of workplace learning: A literature review. Vocations and Learning, 6.

Uhl-Bien, M. \& Arena, M. 2017. Complexity leadership: Enabling people and organizations for adaptability. Organizational Dynamics. 
Vähäsantanen, K., Paloniemi, S., Hökkä, P. \& Eteläpelto, A. 2017. Agentic perspective on fostering work-related learning. Studies in Continuing Education, 1-17.

Watkins, K.E. and Marsick, V.J. 2021. Informal and Incidental Learning in the time of COVID-19. Advances in Developing Human Resources 23(1): 88-96.

Watts, D. \& Strogatz, S. 1998. Collective dynamics of 'small-world' networks. Nature, 393, 440-442. Wilhelmsson, N., Dahlgren, L. O., Hult, H., Scheja, M., Lonka, K. \& Josephson, A. 2010. The anatomy of learning anatomy. Advances in Health Science Education, 15, 153-165.

Xinwei, Y., Lorne, O. \& Jingbing, Y. 2016. How do institution-based trust and interpersonal trust affect interdepartmental knowledge sharing? Information Resources Management Journal (IRMJ), 29, 15-38.

Yates, C., Partridge, H. \& Bruce, C. 2012. Exploring information experiences through phenomenography. Library and Information Research, 36, 96-119. 